\title{
DESIGN METHOD FOR COLD-FORMED STEEL U-SECTION SHORT COLUMNS
}

\author{
Yan-chun Li *, Tian-hua Zhou, Liu-rui Sang and Lei Zhang \\ Department of Civil Engineering, Chang'an University, Xi'an, China \\ * (Corresponding author: E-mail: liyanchun@chd.edu.cn)
}

\section{A B S T RA C T}

The axial bearing properties of cold-formed steel U-section short columns are investigated in this paper, including 12 columns with four types of lengths i.e. $300 \mathrm{~mm}, 360 \mathrm{~mm}, 420 \mathrm{~mm}$, and $450 \mathrm{~mm}$. Then finite element models (FEM) were developed to simulate the experimental specimens and compared with the test results to guarantee the rationality of FEM. Moreover, the width-to-thickness and the height-to-thickness of CFS U-section short columns were examined by FEM. An approach to accurately predict the ultimate capacity of CFS U-section short columns was proposed and certified by a large number of experimental and numerical simulation data, in order to remedy the deficiency that the direct strength method (DSM) has a large error in calculating the ultimate capacity of CFS U-section short columns. Specifically, this paper not only clarified the proposed method depending on the DSM for calculating the ultimate capacity of the CFS U-section columns but also provides reference for practical engineering design and application.

ART I C LE H IS T O RY

\begin{tabular}{ll}
\hline & \\
Received: & 11 June 2019 \\
Revised: & 16 March 2020
\end{tabular}

Accepted: $\quad 29$ March 2020

\section{K E Y W O R D S}

Cold-formed steel;

U-section short columns;

Experiment;

Design method

\section{Introduction}

The cold-formed steel (CFS) structure and design theory of building structures improved the development of thin-walled and lightweight members. Due to the advantages of the diversity of cross sections, good mechanical properties, light material and material saving, while the CFS offering a satisfactory strength to mass ratio and higher post-buckling strength. The common components of CFS, including channel section, Z-section, hat-section, U-section and other single open sections, had been studied quite mature by many scholars [1-10]. Meanwhile, design methods of these simple sections were recorded in the North American Specification (AISIS100) [11] and Australian/New Zealand Standard (AS/NZS 4600) [12], including the effective width method (EWM) and direct strength method (DSM). Moreover, the bearing capacity of the U-section members according to the design methods $[11,12]$ has been studied quite mature by many researchers [13-19], while the research results showed that the ultimate capacity of CFS U-section members calculated by these methods $[11,12]$ has large error and is unsafe. Therefore, it is necessary to propose a design method in calculating the ultimate capacity for CFS U-section short columns, as shown in Fig. 1.

In the past few years, ample studies have been devoted to the structural behavior and ultimate capacity of U-section members at home and abroad. Ungermann et al. [13] conducted an experiment on plain channel short columns. The research results demonstrated that short column subjected to local buckling only and an approach for an approximation of effective stiffness for coupled instabilities was proposed based on eurocode 3. Loughlan [14] developed numerical studies for fixed-end plain channel columns to examine them interaction of the local-overall flexural and the influence on behavior of local conditions at the plate ends. The results indicated that different boundary conditions resulted in quite different buckling responses of the U-section columns. An experimental research investigating the buckling and ultimate capacity of the CFS plain and dimpled steel columns was conducted by Nguyen et al. [15]. The studies revealed that the buckling and ultimate capacities of dimpled steel columns were up to $33 \%$ and $26 \%$ greater than plain steel columns, respectively. Duarte [16] presented the experimental and numerical study of CFS plain channel beams. Based on the slenderness concept, a new slenderness-based approach for the web crippling design was proposed. CFS plain channel members were researched by Young [17-19] according to experiments and numerical analyses. The buckling modes and design method were studied by his team.

In this paper, the buckling modes and ultimate capacities of CFS U-section short columns were investigated by the experiment and numerical simulations. Extensive parameters studies were carried out to study the influence of the width-thickness ratio and the height-thickness ratio of the cross-section on ultimate capacities and buckling modes of CFS U-section short columns. Depending on the experimental results and parametric study, an approach to predict the ultimate capacity of CFS U-section short columns was proposed based on the DSM. Then the results obtained by the modified method compared with the data obtained from experiment, FEM and the DSM
[11], in order to verify the accuracy of the modified method.

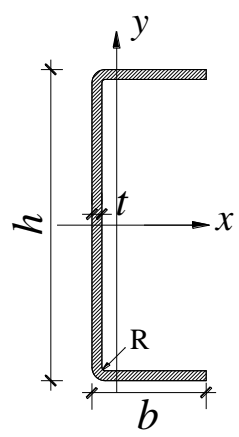

Fig. 1 U-shaped cross-section

\section{Experimental design}

\subsection{Test setup}

The POPWILL structure testing machine system and counterforce portal frame were utilized to apply a vertical load in this test. DH3820 static strain testing system was implemented to collect the data of strains and displacements. The loading device was illustrated in Fig. 2. The steel end plates with a thickness of $16 \mathrm{~mm}$ were welded to both ends of the members in order to fix the column. In order to eliminate the adverse influence of axial force shifting with the occurrence of local buckling [20], the specimens were placed directly on the testing rig to simulate the fixed-ended boundary condition, as shown in Fig. 2(b).

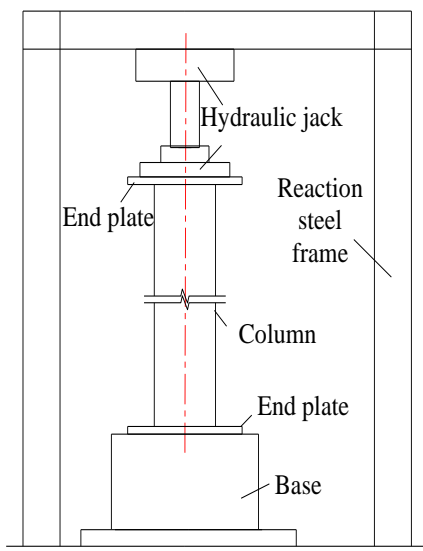

(a) Sketch Map

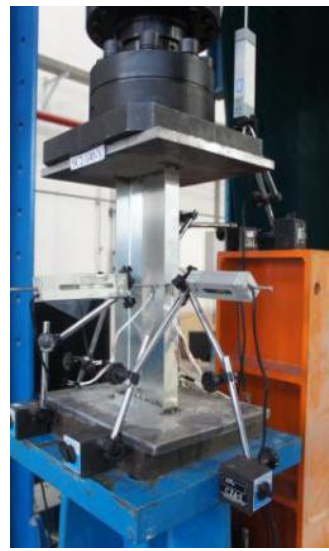

(b) Practicality picture
Fig. 2 Test set-up 


\subsection{Specimens design}

The CFS U-section short columns were shown in Fig. 1. Referring to the technical specification for CFS structure [21], four kinds of cross-sectional dimensions were designed, as listed in Table 1, and the labeling rule of specimens was presented in Fig. 3. Four kinds of lengths, 300mm, 360mm, $420 \mathrm{~mm}, 450 \mathrm{~mm}$, were designed in this study. The details of the U-section short column were summarized in Table 1 .

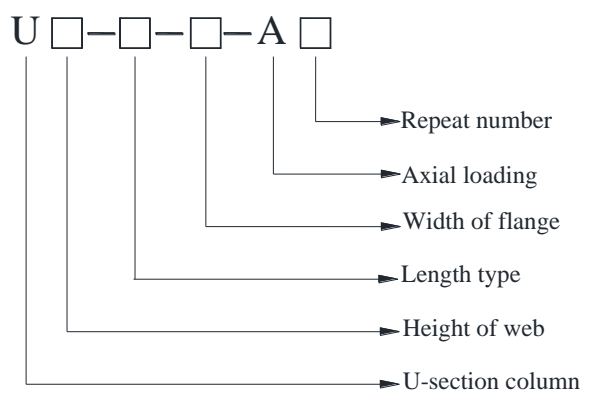

Fig. 3 Labeling rule of specimens

Table 1

Measured dimensions and failure loads of U-section short columns

\begin{tabular}{|c|c|c|c|c|c|c|c|c|c|c|c|c|c|c|c|}
\hline \multirow{2}{*}{ Specimen } & \multirow{2}{*}{$l / \mathrm{mm}$} & \multicolumn{7}{|c|}{ Geometric imperfection/mm } & \multicolumn{5}{|c|}{ Cross-section dimension/mm } & \multicolumn{2}{|c|}{ Test results } \\
\hline & & $\Delta_{\mathrm{lfl}}$ & $\Delta_{\mathrm{rfl}}$ & $\Delta_{\mathrm{lf}}$ & $\Delta_{\mathrm{rf}}$ & $\Delta_{\mathrm{w}}$ & $\delta_{1}$ & $\delta_{2}$ & $h$ & $b_{1}$ & $b_{2}$ & $t$ & $A / \mathrm{mm}^{2}$ & $P_{\mathrm{u}} / \mathrm{kN}$ & Mode \\
\hline U90-300-35-A1 & 298 & 1.00 & 1.50 & 0.30 & 0.20 & 0.35 & 2.50 & 0.02 & 96.00 & 36.10 & 35.20 & 1.19 & 199.10 & 36.80 & $\mathrm{~L}$ \\
\hline U90 -300-35-A2 & 302 & 1.55 & 2.65 & 0.58 & 0.15 & 0.15 & 1.25 & 0.04 & 96.00 & 37.00 & 35.80 & 1.18 & 199.20 & 34.80 & $\mathrm{~L}$ \\
\hline U90-300-35-A3 & 299 & 3.50 & 2.00 & 0.95 & 0.27 & 0.30 & 4.00 & 0.06 & 98.00 & 35.50 & 36.80 & 1.19 & 202.70 & 34.00 & $\mathrm{~L}$ \\
\hline U120-360-50-A1 & 361 & 2.70 & 0.75 & 0.20 & 0.55 & 0.20 & 3.25 & 0.55 & 123.00 & 53.50 & 56.50 & 1.17 & 276.70 & 36.81 & $\mathrm{~L}$ \\
\hline U120-360-50-A2 & 361 & 0.50 & 0.95 & 0.65 & 0.85 & 0.15 & 1.15 & 0.85 & 125.00 & 55.00 & 58.00 & 1.17 & 282.70 & 34.86 & $\mathrm{~L}$ \\
\hline U120-360-50-A3 & 359 & 1.95 & 0.30 & 1.55 & 0.60 & 1.45 & 1.95 & 0.60 & 124.00 & 54.00 & 57.00 & 1.15 & 279.10 & 39.28 & $\mathrm{~L}$ \\
\hline U140-420-50-A1 & 421 & 0.95 & 0.00 & 0.90 & 0.30 & 0.50 & 0.02 & 0.30 & 145.00 & 43.50 & 43.00 & 1.17 & 307.80 & 38.20 & $\mathrm{~L}$ \\
\hline U140-420-50-A2 & 422 & 3.30 & 0.95 & 0.55 & 2.50 & 0.35 & 2.65 & 2.50 & 145.00 & 43.80 & 43.30 & 1.14 & 298.10 & 39.59 & $\mathrm{~L}$ \\
\hline U140-420-50-A3 & 422 & 0.80 & 2.70 & 0.10 & 0.80 & 0.70 & 0.25 & 0.80 & 145.00 & 43.50 & 43.00 & 1.17 & 307.80 & 38.80 & $\mathrm{~L}$ \\
\hline U140-450-35-A1 & 452 & 0.02 & 0.00 & 0.10 & 0.25 & 0.17 & 0.14 & 0.20 & 148.00 & 37.00 & 36.00 & 1.48 & 327.10 & 47.70 & $\mathrm{~L}$ \\
\hline U140-450-35-A2 & 452 & 0.60 & 0.60 & 0.08 & 0.18 & 0.38 & 0.04 & 0.17 & 147.00 & 35.00 & 37.00 & 1.49 & 326.30 & 48.10 & $\mathrm{~L}$ \\
\hline U140-450-35-A3 & 452 & 1.65 & 1.25 & 0.02 & 0.10 & 0.15 & 1.45 & 0.38 & 147.20 & 36.00 & 36.10 & 1.49 & 326.80 & 44.00 & $\mathrm{~L}$ \\
\hline
\end{tabular}

Note: $1 . A_{\mathrm{g}}=\left(h+b_{1}+b_{1}\right) \times t ; P_{\mathrm{u}}$ is the ultimate capacity; $P_{\mathrm{y}}=f_{\mathrm{y}} \times A_{\mathrm{g}}$, where $f_{\mathrm{y}}$ is the yield stress. $2 . \mathrm{L}$ means local buckling.

\subsection{Material characterization}

The material properties of basic components adopted in the test were measured according to the codes GB/T228.1-2010 [22]. According to the different thicknesses, two groups of specimens were designed: $t_{1}=1.2 \mathrm{~mm}$, $t_{2}=1.5 \mathrm{~mm}$, as listed in Table 2. T1.2 means that the thickness is $1.2 \mathrm{~mm}$ and the second number refers to the repeated number. In addition, the stress-strain curves are presented in Fig. 4.

Table 2

Nominal and measured material properties obtained from tensile coupon tests

\begin{tabular}{cccccccc}
\hline Specimen & $f_{\mathrm{y}} / \mathrm{MPa}$ & Mean & $f_{\mathrm{u}} / \mathrm{MPa}$ & Mean & $E / \mathrm{GPa}$ & Mean & Elongation \\
\hline $\mathrm{T} 1.2-1$ & 332.91 & & 451.65 & & 2.029 & & 32.0 \\
$\mathrm{~T} 1.2-2$ & 331.62 & 334.51 & 452.42 & 453.18 & 2.071 & 2.065 & 36.0 \\
$\mathrm{~T} 1.2-3$ & 338.99 & & 455.46 & & 2.096 & & 31.0 \\
$\mathrm{~T} 1.5-1$ & 293.56 & & 353.91 & & 1.890 & & 40.0 \\
$\mathrm{~T} 1.5-2$ & 285.98 & 289.24 & 347.33 & 350.76 & 1.900 & 1.898 & 42.0 \\
$\mathrm{~T} 1.5-3$ & 306.70 & & 366.70 & & 2.050 & & 33.9 \\
\hline
\end{tabular}

Note: $f_{\mathrm{y}}$ - the yield stress; $f_{\mathrm{u}}$ - the ultimate stress; $E$ - Elastic modulus

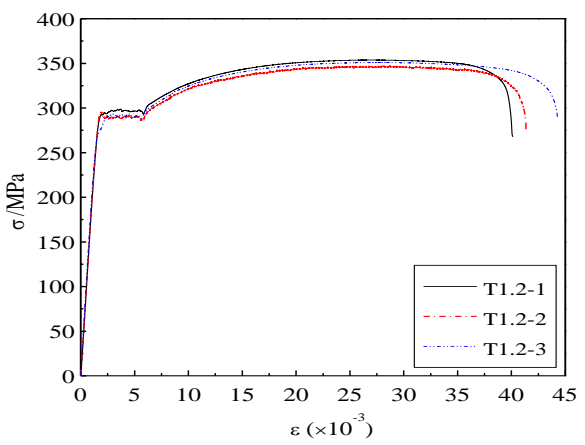

(a)

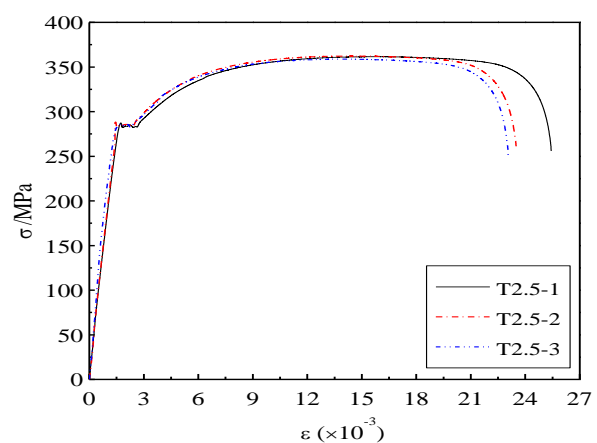

(b)

Fig. 4 Stress vs. strain curve. (a) $t=1.2$. (b) $t=1.5$

\subsection{Geometric Imperfections}

In this study, the initial geometric imperfections of specimens, including local and global imperfections, were measured. Local imperfection refers to the flatness of the plate and the angle between the components, as shown in Fig. 6. The specimens were fixed on the measuring platform and the rigid rod was placed on the selected plate (see Fig. 6), measuring a value with a percentile meter, and then removing the rigid rod to measure a value, finally, subtracting the former value from the latter, that is, the local initial imperfection of the plate, as listed in Table 1 .

In addition, the initial geometrical imperfection of overall is the derivation of the vertical degree of the specimen. A dial indicator was used to assess the initial bending of the test members (see Fig. 7). When measuring the initial bending of specimens, specimens were fixed on the measuring platform, and then two values were measured at the two ends of members. Then an average value was measured in the middle of specimens. The latter value was utilized to subtract the average value in front of specimens, that is, the initial bending of specimens (see Table 1). 


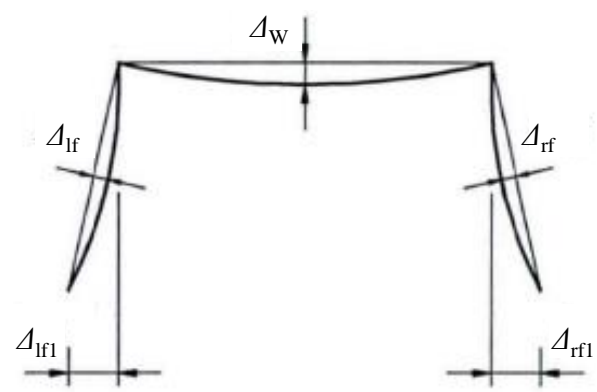

Fig. 5 Local imperfection

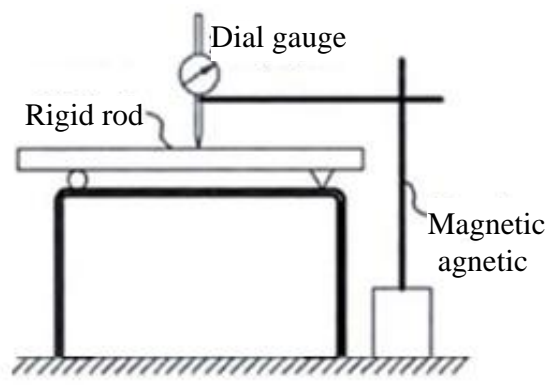

Fig. 6 Device of local imperfection

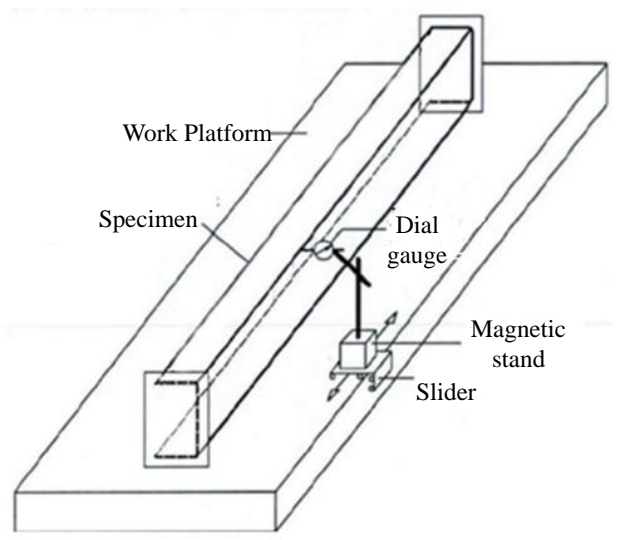

Fig. 7 Device of overall imperfections

\section{Experimental results}

\subsection{Failure modes}

\subsubsection{U90 series column}

The local buckling occurred (Fig. 8) on flanges of the U90-300-35-A1 A3 specimen as load increased to $15.4 \mathrm{kN}$, while the slight local buckling emerged on flanges of the A2 and A3 specimens when the load reached approximately $18 \mathrm{kN}$. The failure modes were presented in Table 1.
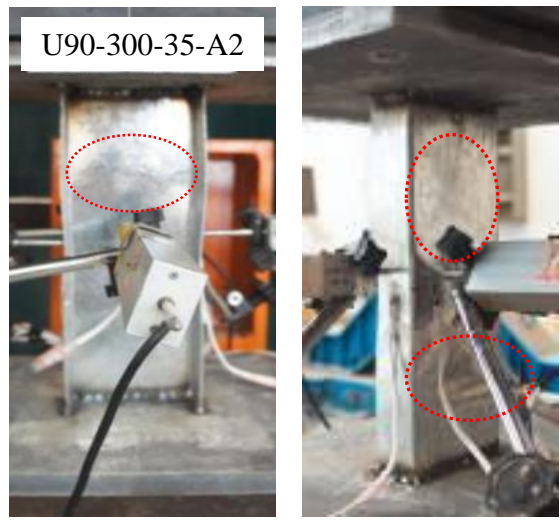
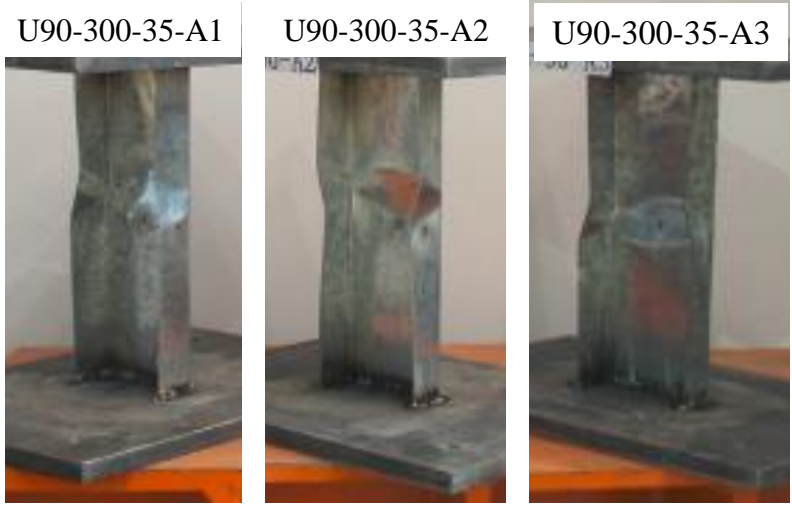

(b) Failure comparison of A1, A2 and A3 specimens

Fig. 8 Experimental phenomena of the U90-300-35-A series specimens

\subsubsection{U120 series column}

Fig. 9 shows the local buckling failure modes of U120-360-50-A1 A3 specimens subjected to axial pressure. There were no obvious local buckling deformation on the web at the initial stage of loading attributed to the strong welding between the end of the specimen and plates. The failure modes were indicated in Table 1.
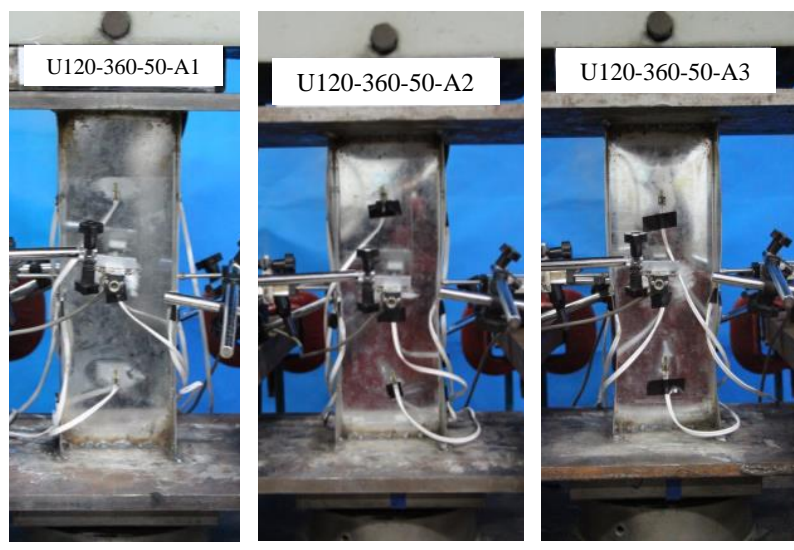

(a) Local buckling of $\mathrm{A} 1, \mathrm{~A} 2$ and $\mathrm{A} 3$ specimens

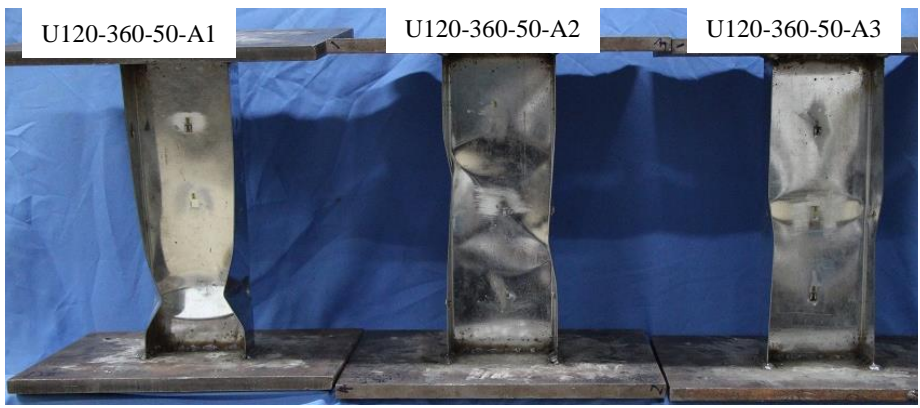

(b) Failure characteristics of A1, A2 and A3 specimens

Fig. 9 Experimental phenomena of the U120-360-50-A series specimens

\subsubsection{U140 series column}

Failure characteristics of U140-420-50-A1 A3 specimens were as follows: in the process of loading, local buckling occurred on flanges for the three specimens, but no obvious local buckling deformation occurred on the web. Ideally, plastic yielding occurred in the cross-sections of all three specimens when the load reached about $39 \mathrm{kN}$. Ultimately, all three specimens were damaged due to the local depression of webs and the extension of flanges, as shown in Fig. 10. The failure modes were presented in Table 1. 

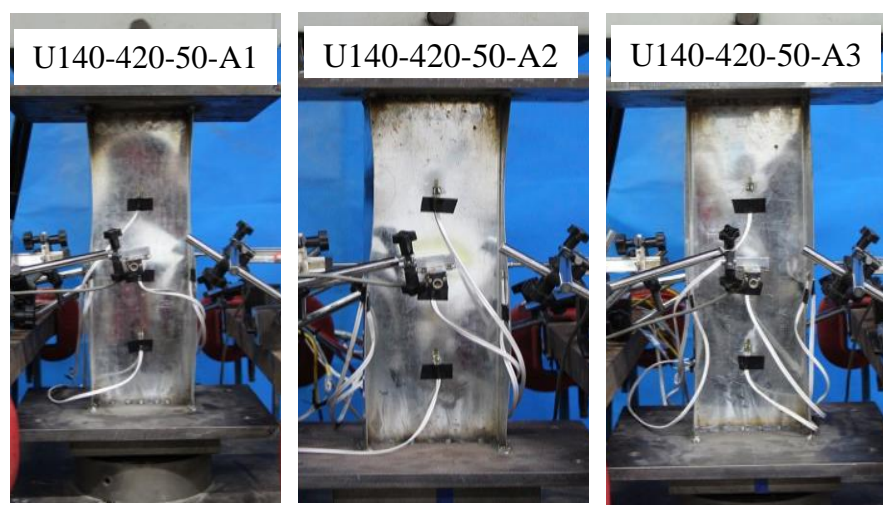

(a) Local buckling of $\mathrm{A} 1, \mathrm{~A} 2$ and $\mathrm{A} 3$ specimens

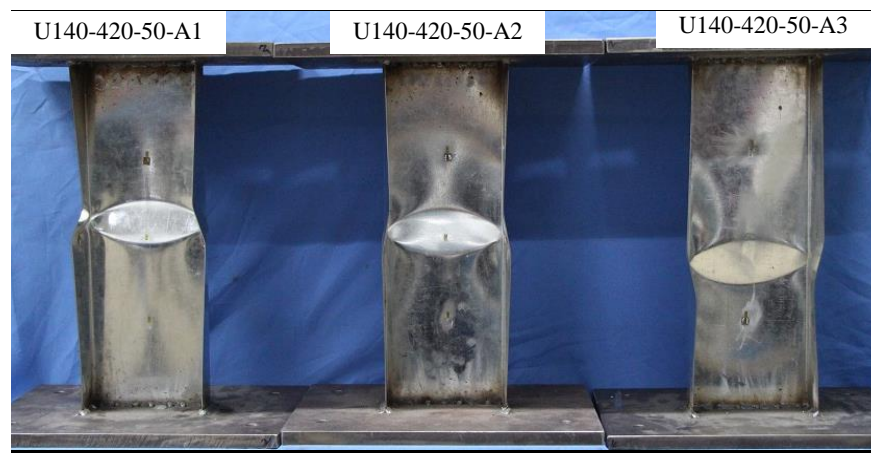

(b) Failure characteristics of A1, A2 and A3 specimens

Fig. 10 Experimental phenomena of the U140-420-50-A series specimens

For U140-450-35-A series columns, due to the specimens were welded strongly on the steel plate, the end of the specimens was not crushed and there was no obvious local buckling deformation on the web at the initial loading stage. Subsequently, with the increase of load, the experimental phenomena of specimens were the same as the U140-450-35-A1 A3 specimens, as shown in Fig. 11. The failure modes were indicated in Table 1.
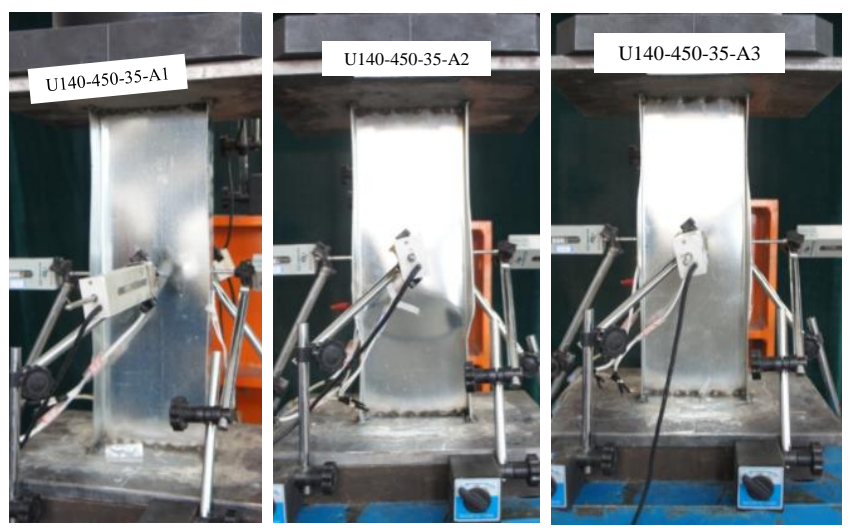

(a) Local buckling of A1, A2 and A3 specimens

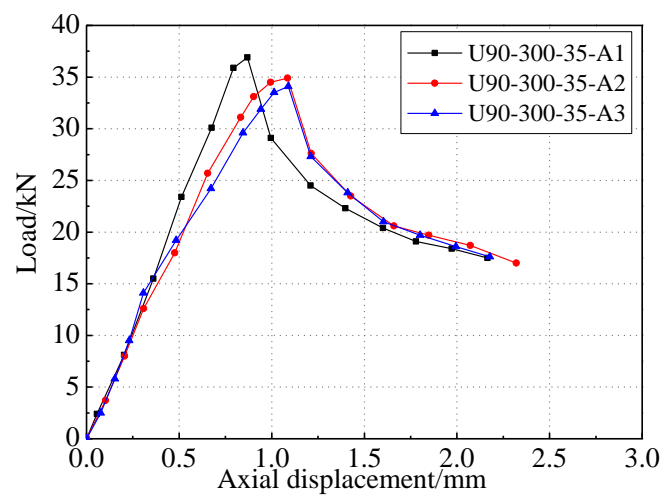

(a)

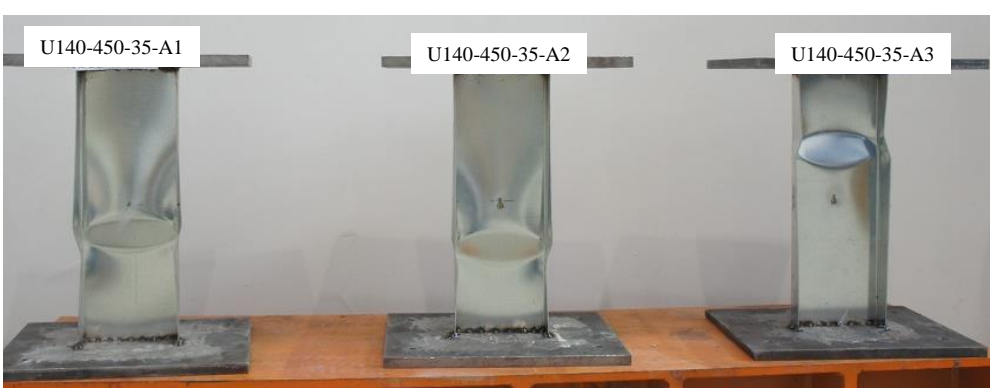

(b) Failure characteristics of A1, A2 and A3 specimens

Fig. 11 Experimental phenomena of the U140-450-35-A series specimens

\subsection{Axial load-displacement curve}

Fig. 12 exhibits the load-displacement curve of specimens with four types of lengths i.e. $300 \mathrm{~mm}, 360 \mathrm{~mm}, 420 \mathrm{~mm}$, and $450 \mathrm{~mm}$. In the initial loading period, load-axial displacement curves of all the specimens were basically linear and smooth due to the stable stiffness of the test specimens. When loaded to the ultimate load, the curve showed a downward trend. The stiffness of the specimens decreased significantly, indicating that the test specimens have been damaged. It is obvious that the experimental phenomena, variation trend and ultimate capacity of the three specimens in each group were similar. The phenomenon indicated the accuracy and reliability of the experiment could be guaranteed.

\section{The finite element analysis}

\subsection{Development of finite element model}

The finite element software ABAQUS [23] was utilized in this study to establish the finite element model (FEM). The measured geometric dimensions, initial geometric imperfections and material properties (see Table 2) of the test specimens were applied to the FEM.

The column was simulated by shell element, and the element type was the four-node linear reduction integral element S4R. The more accurate results can be obtained when the mesh of specimens was $5 \mathrm{~mm} \times 5 \mathrm{~mm}$. In this paper, the end of the test specimens was attached to the steel plate with a thickness of $16 \mathrm{~mm}$ by welding. Because the stiffness of the end plate was larger than that of the specimens, the analytical stiffness was established at the end of the specimen to save the calculation cost. The rigid body displacement was controlled by the reference points on both sides of the model (RP1 and RP2 in Fig. 13). The fixed-ended boundary condition of the short columns was simulated in the FEA by restraining all degree of freedom at both ends of the FEM specimens, except for the translational degree of freedom in the axial loading direction (see Fig. 13). The same as the experiment, the displacement loading control method was employed in the FEA.

Inevitably, there were some imperfections in the fabrication process of cold-formed steel. For the geometric imperfection, the FEM captured the instability deformation modes according to the measured plate irregularity and the initial bending of the specimen. The initial imperfection for local instability and overall instability was advised by Zhang and Young [24].

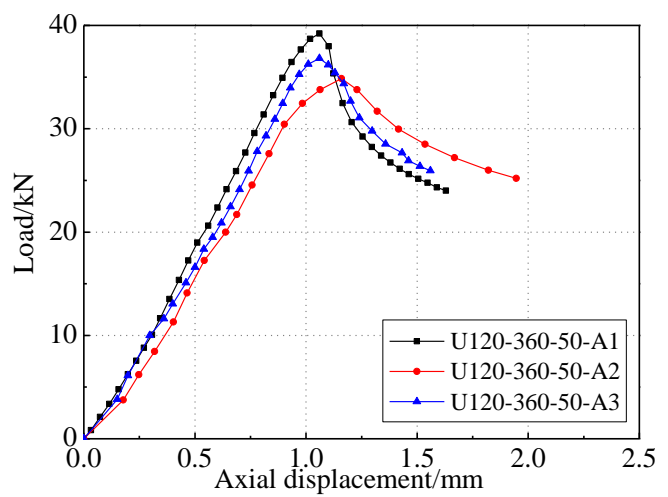

(b) 


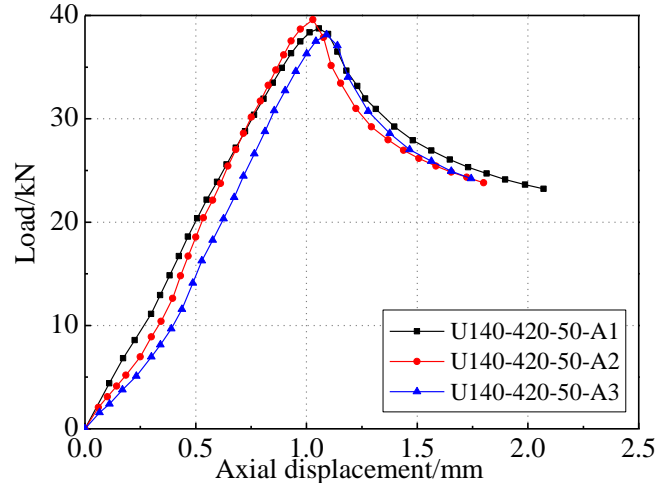

(c)

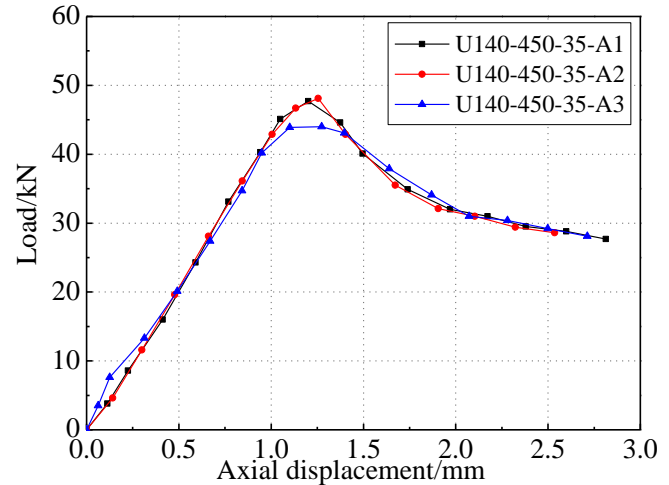

(d)

Fig. 12 Load-Axial displacement curves of specimen

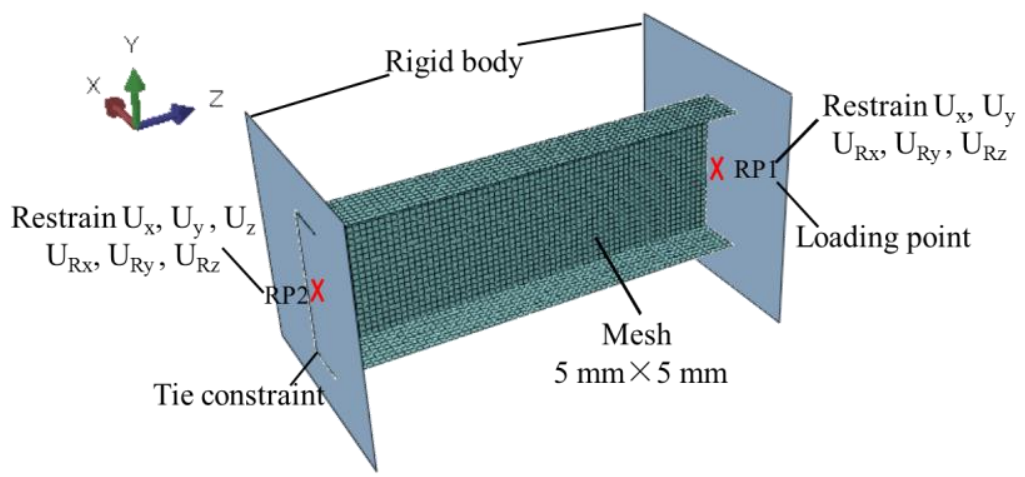

Fig. 13 Finite element mode

\subsection{Validated of finite element model}

The finite element models were verified by the CFS U-section columns in this study. The results obtained from the FEA $\left(P_{\mathrm{FEA}}\right)$ were compared with the test results $\left(P_{\mathrm{u}}\right)$, as listed in Table 3 . The mean value of the $P_{\mathrm{FEA}} / P_{\mathrm{u}}$ ratio is 1.05 , with the standard deviation (SD) of 0.041 . It can be observed that the ultimate capacity and failure mode obtained by the test and FEA is basically the same. What's more, the failure modes and failure position of the experimental specimens are the same as those predicted by FEA, as presented in Fig. 14. As expected, the comparison results clearly indicate that the FEA results are in good agreement with the experimental results. Therefore, the FEM is accurate and reliable in this paper.

Table 3

Comparison of the results of result and finite element analysis

\begin{tabular}{cccccc}
\hline \multirow{2}{*}{ Specimen } & \multicolumn{2}{c}{ FEA results } & \multicolumn{2}{c}{ Test results } & \multirow{2}{*}{$P_{\text {FEA }} / P_{\mathrm{u}}$} \\
\cline { 2 - 5 } & $P_{\text {FEA }} / \mathrm{kN}$ & Mode & $P_{\mathrm{u} / \mathrm{kN}}$ & Mode & \\
\hline U90-300-35-A1 & 37.26 & $\mathrm{~L}$ & 36.82 & $\mathrm{~L}$ & 1.01 \\
U90 -300-35-A2 & 35.60 & $\mathrm{~L}$ & 34.86 & $\mathrm{~L}$ & 1.02 \\
U90-300-35-A3 & 36.23 & $\mathrm{~L}$ & 34.23 & $\mathrm{~L}$ & 1.06 \\
U120-360-50-A1 & 37.82 & $\mathrm{~L}$ & 36.81 & $\mathrm{~L}$ & 1.03 \\
U120-360-50-A2 & 35.38 & $\mathrm{~L}$ & 34.86 & $\mathrm{~L}$ & 1.01 \\
U120-360-50-A3 & 39.62 & $\mathrm{~L}$ & 39.28 & $\mathrm{~L}$ & 1.01 \\
U140-420-50-A1 & 40.58 & $\mathrm{~L}$ & 38.24 & $\mathrm{~L}$ & 1.06 \\
U140-420-50-A2 & 40.85 & $\mathrm{~L}$ & 39.59 & $\mathrm{~L}$ & 1.03 \\
U140-420-50-A3 & 40.98 & $\mathrm{~L}$ & 38.82 & $\mathrm{~L}$ & 1.06 \\
U140-450-35-A1 & 51.69 & $\mathrm{G}$ & 47.79 & $\mathrm{~L}$ & 1.08 \\
U140-450-35-A2 & 52.13 & $\mathrm{G}$ & 48.15 & $\mathrm{~L}$ & 1.08 \\
U140-450-35-A3 & 51.43 & $\mathrm{G}$ & 44.36 & $\mathrm{~L}$ & 1.16 \\
\hline Mean & & & & & 1.05 \\
SD & & & & & 0.041 \\
\hline
\end{tabular}

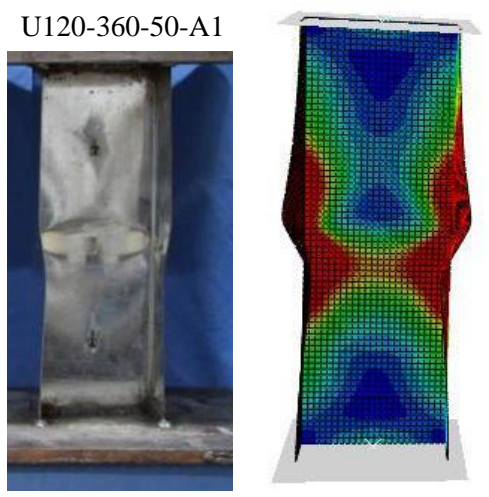

(b)

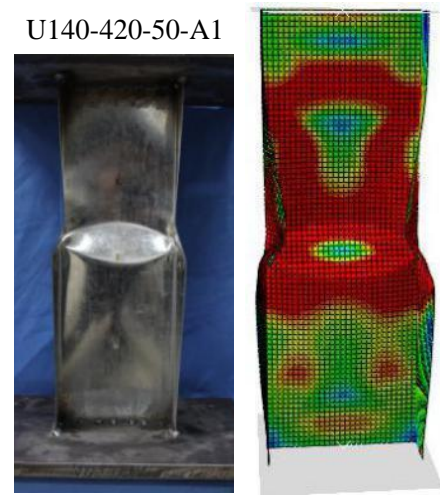

(c) 


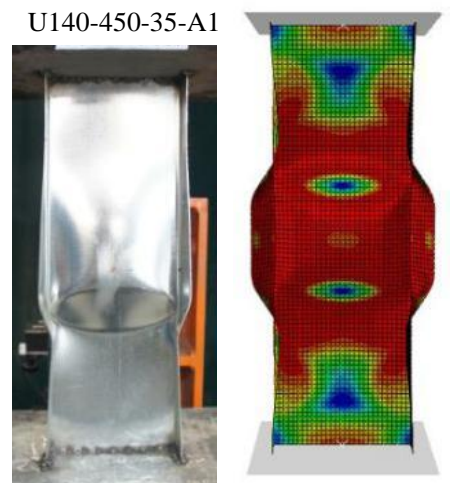

(d)

Fig. 14 Comparisons of failure modes and locations between test and finite element

\subsection{Parametric studies}

The length of specimens was designed to be about three times the web height (see Table 4) according to American Structural Stability Association. In this paper, a total of 64 FEM are designed by changing the height of webs, the width of flanges, and the thickness of the section. The results obtained by FEA were listed in Table 4, and the following points can be summarized by analysis results:

1.With the height and thickness of webs unchanged, the ultimate capacities of members increased with the increase of the width-thickness ratio of flanges. The phenomenon was mainly attributed to the enhanced constraint of flanges on the web with the increase of the width-thickness ratio of flanges. Therefore, the more difficult the web is to buckle, the higher the ultimate capacities of members will be.

2.The height of webs and the width of flanges remained unchanged, the ultimate capacities of all members were increased by increasing the thickness, and the increase of the ultimate capacity was very significant. This is mainly due to the increase of the thickness, for one thing, the buckling capacity of a single plate was improved, for another, the moment of inertia of member section was increased.

3. With the same flange width and thickness, increasing the height-thickness ratio of webs cannot significantly improve the ultimate capacity of U-section short columns. On one hand, the increase of web height-thickness ratios resulted in the decrease of the critical local buckling load, which led to local buckling more easily, and then affected the ultimate capacity of members. On the other hand, the inertia moment of the section around the weak axis increased slightly with the increase of web height-thickness ratios, which was the reason why simply increasing web height-thickness ratio cannot obviously improve the ultimate capacity of specimens.

Table 4

The parametric analysis of CFS U-section short columns

\begin{tabular}{|c|c|c|c|c|c|c|c|c|c|}
\hline Specimen & $l / \mathrm{mm}$ & $b / t$ & $h / t$ & $P_{\mathrm{FEA}}$ & Specimen & $l / \mathrm{mm}$ & $P_{\mathrm{FEA}}$ & $b / t$ & $h / t$ \\
\hline U140-20-1.0 & 420 & 20 & 140 & 25.18 & U100-20-1.0 & 300 & 24.57 & 20 & 100 \\
\hline U140-20-1.5 & 420 & 13.33 & 93.33 & 48.25 & U100-20-1.5 & 300 & 47.73 & 13.33 & 66.67 \\
\hline U140-20-2.0 & 420 & 10 & 70 & 74.65 & U100-20-2.0 & 300 & 73.96 & 10 & 50 \\
\hline U140-20-2.5 & 420 & 8 & 56 & 105.39 & U100-20-2.5 & 300 & 101.45 & 8 & 40 \\
\hline U140-40-1.0 & 420 & 40 & 140 & 30.32 & U100-40-1.0 & 300 & 28.59 & 40 & 100 \\
\hline U140-40-1.5 & 420 & 26.67 & 93.33 & 58.36 & U100-40-1.5 & 300 & 57.13 & 26.67 & 66.67 \\
\hline U140-40-2.0 & 420 & 20 & 70 & 93.85 & U100-40-2.0 & 300 & 91.83 & 20 & 50 \\
\hline U140-40-2.5 & 420 & 16 & 56 & 136.94 & U100-40-2.5 & 300 & 130.7 & 16 & 40 \\
\hline U140-60-1.0 & 420 & 60 & 140 & 32.11 & U100-60-1.0 & 300 & 31.07 & 60 & 100 \\
\hline U140-60-1.5 & 420 & 40 & 93.33 & 65.16 & U100-60-1.5 & 300 & 64.1 & 40 & 66.67 \\
\hline U140-60-2.0 & 420 & 30 & 70 & 104.21 & U100-60-2.0 & 300 & 103.75 & 30 & 50 \\
\hline U140-60-2.5 & 420 & 24 & 56 & 151.67 & U100-60-2.5 & 300 & 149.15 & 24 & 40 \\
\hline U140-80-1.0 & 420 & 80 & 140 & 32.69 & U100-80-1.0 & 300 & 32.89 & 80 & 100 \\
\hline U140-80-1.5 & 420 & 53.33 & 93.33 & 68.1 & U100-80-1.5 & 300 & 66.8 & 53.33 & 66.67 \\
\hline U140-80-2.0 & 420 & 40 & 70 & 114.38 & U100-80-2.0 & 300 & 113.63 & 40 & 50 \\
\hline U140-80-2.5 & 420 & 32 & 56 & 166.05 & U100-80-2.5 & 300 & 163.9 & 32 & 40 \\
\hline U120-20-1.0 & 360 & 20 & 120 & 24.92 & U80-20-1.0 & 240 & 23.96 & 20 & 80 \\
\hline U120-20-1.5 & 360 & 13.33 & 80 & 47.79 & U80-20-1.5 & 240 & 46.99 & 13.33 & 53.33 \\
\hline U120-20-2.0 & 360 & 10 & 60 & 74.54 & U80-20-2.0 & 240 & 71.07 & 10 & 40 \\
\hline U120-20-2.5 & 360 & 8 & 48 & 103.28 & U80-20-2.5 & 240 & 93.49 & 8 & 32 \\
\hline U120-40-1.0 & 360 & 40 & 120 & 29.48 & U80-40-1.0 & 240 & 29.03 & 40 & 80 \\
\hline U120-40-1.5 & 360 & 26.67 & 80 & 57.84 & U80-40-1.5 & 240 & 56.8 & 26.67 & 53.33 \\
\hline U120-40-2.0 & 360 & 20 & 60 & 92.15 & U80-40-2.0 & 240 & 90.38 & 20 & 40 \\
\hline U120-40-2.5 & 360 & 16 & 48 & 132.71 & U80-40-2.5 & 240 & 123.92 & 16 & 32 \\
\hline U120-60-1.0 & 360 & 60 & 120 & 31.61 & U80-60-1.0 & 240 & 31.25 & 60 & 80 \\
\hline U120-60-1.5 & 360 & 40 & 80 & 64.32 & U80-60-1.5 & 240 & 65.58 & 40 & 53.33 \\
\hline U120-60-2.0 & 360 & 30 & 60 & 104.5 & U80-60-2.0 & 240 & 103.45 & 30 & 40 \\
\hline U120-60-2.5 & 360 & 24 & 48 & 151.21 & U80-60-2.5 & 240 & 145.84 & 24 & 32 \\
\hline U120-80-1.0 & 360 & 80 & 120 & 32.42 & U80-80-1.0 & 240 & 31.56 & 80 & 80 \\
\hline U120-80-1.5 & 360 & 53.33 & 80 & 68.43 & U80-80-1.5 & 240 & 69 & 53.33 & 53.33 \\
\hline U120-80-2.0 & 360 & 40 & 60 & 114.03 & U80-80-2.0 & 240 & 110.96 & 40 & 40 \\
\hline U120-80-2.5 & 360 & 32 & 48 & 165.67 & U80-80-2.5 & 240 & 155.99 & 32 & 32 \\
\hline
\end{tabular}

Note: U140-20-1.0, 140-the height of web $(h) ; 20$-the width of flange $(b) ; 1.0$-the thickness of section $(t) ; P_{\mathrm{FEA}}$-the ultimate capacity obtained by the finite element analysis. 


\section{Design methods}

The direct strength method (DSM) was proposed by Schafer and Pekoz $[25,26]$. The DSM in the current North American Specification [11] and Australian/New Zealand Standard (AS/NZS) [12] applies only to simple single-limb sections, such as C-section, C-section with web stiffened, Z-section, $\mathrm{R}$-section and hat-section. However, it is strongly associated with the geometric parameters and physical parameters of the specimens selected by Schafer in DSM. Therefore, whether the DSM is suitable for CFS U-section short columns remains to be studied.

\subsection{Elastic buckling stress}

The buckling mode and the corresponding elastic buckling stress are first determined for calculation using the DSM. These buckling modes and elastic buckling stresses are availed from the generalized beam theory software (GBTUL) [27].

\subsection{Current direct strength method (CDSM)}

The currently available DSM strength expressions, already included in AISI [11] and AS/NZS [12], provided an effective approach to estimate the ultimate capacity of CFS members subjected to columns or beams and failing in local buckling (L), distortional buckling (D), global buckling (G) or local-global buckling (LG) interactive modes. In the case of columns, the nominal strength is given by the expressions:

$P_{\mathrm{n}}=\min \left(P_{\mathrm{ne}}, P_{\mathrm{nl}}\right.$, and $\left.P_{\mathrm{nd}}\right)$

$P_{n e}= \begin{cases}\left(0.658^{\lambda_{c}{ }^{2}}\right) P_{y} & \text { if } \lambda_{c} \leq 1.5 \\ \left(\frac{0.877}{\lambda_{c}{ }^{2}}\right) P_{y} & \text { if } \lambda_{c}>1.5\end{cases}$

$P_{n e l}= \begin{cases}P_{n e} & \text { if } \lambda_{l} \leq 0.776 \\ {\left[1-0.15\left(\frac{P_{c r l}}{P_{n e}}\right)^{0.4}\right]\left(\frac{P_{c r l}}{P_{n e}}\right)^{0.4} P_{y} \text { if } \quad \lambda_{l}>0.776}\end{cases}$

$P_{n d}= \begin{cases}P_{y} & \text { if } \lambda_{l} \leq 0.561 \\ {\left[1-0.25\left(\frac{P_{c r d}}{P_{y}}\right)^{0.6}\right]\left(\frac{P_{c r d}}{P_{y}}\right)^{0.6} P_{y}} & \text { if } \quad \lambda_{l}>0.561\end{cases}$

where $\lambda_{\mathrm{c}}=\left(P_{\mathrm{y}} / P_{\mathrm{cre}}\right)^{0.5}, \quad \lambda_{\mathrm{l}}=\left(P_{\mathrm{y}} / P_{\mathrm{crl}}\right)^{0.5}, \quad \lambda_{\mathrm{d}}=\left(P_{\mathrm{y}} / P_{\mathrm{crd}}\right)^{0.5}, \quad P_{\mathrm{y}}=A_{\mathrm{g}} * f_{\mathrm{y}}, \quad P_{\mathrm{crl}}=A_{\mathrm{g}} * f_{\mathrm{crl}}$, $P_{\text {crd }}=A_{\mathrm{g}} * f_{\text {crd }} ; A_{\mathrm{g}}$ is the gross cross-section area; $f_{\mathrm{y}}$ is the yield strength of steel; $P_{\text {cre }}, P_{\text {crl }}$, and $P_{\text {crd }}$ are the elastic critical local, distortional and overall buckling load, respectively. $P_{\mathrm{ne}}, P_{\mathrm{nl}}$, and $P_{\mathrm{nd}}$ are the nominal overall buckling strength, local buckling strength, and distortional buckling strength, respectively.

\subsection{Modified direct strength method (MDSM)}

Based on experiments, parametric analysis and Mulligan [28], this paper presents a method in calculating the ultimate capacities of CFS U-section short columns, as presented in Table 5. According to the above tests and extensive numerical simulation, only local buckling occurs in short columns, therefore, the formula of DSM designed in this paper only includes local buckling under axial compression, as shown in Eq. (5).

$P_{n l}= \begin{cases}P_{y} & \text { if }, \lambda_{l} \leq 0.528 \\ {\left[1-0.24\left(\frac{P_{c r l}}{P_{y}}\right)^{0.4}\right]\left(\frac{P_{c r l}}{P_{y}}\right)^{0.4} P_{y}} & \text { if , } \lambda_{l}>0.528\end{cases}$

where $\lambda_{\mathrm{l}}=\left(P_{\mathrm{y}} / P_{\mathrm{crl}}\right)^{0.5}, P_{\mathrm{y}}=A^{*} f_{\mathrm{y}}, P_{\mathrm{crl}}=A^{*} f_{\text {crl }}, P_{\text {crl }}$ is the elastic critical local buckling load. $f_{\text {crl }}$ is the elastic critical local buckling stress. $f_{\mathrm{y}}$ is the yield stress of the material. $A$ is the gross cross-section area.

\section{Comparison of experimental and numerical results with design pre- dictions}

The results obtained from the experiment $\left(P_{\mathrm{EXP}}\right)$ and the FEA $\left(P_{\mathrm{FEA}}\right)$ were compared with the DSM $\left(P_{\mathrm{CDSM}}\right)$ and the modified DSM $\left(P_{\mathrm{MDSM}}\right)$ in order to verify the validity of the modified method, as shown in Table 5 and Fig. 15. It is clear that the results $P_{\mathrm{CDSM}}$ are generally unsafe with almost all data and the curve, while the results $P_{\text {MDSM }}$ are generally conservative and reliable due to the $\left(P_{\mathrm{EXP}}\right.$ and $\left.P_{\mathrm{FEA}}\right) / P_{\mathrm{CDSM}}$ ratio mean value of 0.93 with the standard deviation (SD) of 0.059 . The mean value of the $\left(P_{\mathrm{EXP}}\right.$ and $\left.P_{\mathrm{FEA}}\right) / P_{\mathrm{MDSM}}$ ratio is 1.01 with the SD of 0.056. It is demonstrated that the column strength obtained by the DSM was not safe and unreliable, which are compared with the results of the experimental and the FEA. Furthermore, it can be seen that the modified method agree well with the experiment and FEA results, as shown in Fig. 15. Hence, the proposed method can be used to predict the ultimate capacity of CFS U-section short columns and provides more reasonable design curves for CFS U-section short columns.

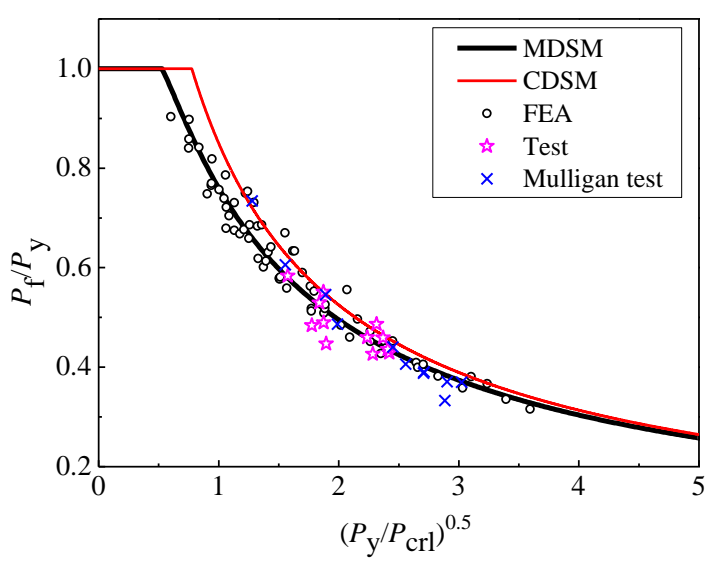

Fig. 15 Modification of the direct strength method

Table5

Comparison of numerical and experimental results with design strengths

\begin{tabular}{|c|c|c|c|c|c|c|}
\hline \multirow{3}{*}{ Source } & \multirow{3}{*}{ Specimen } & \multirow{3}{*}{$\begin{array}{c}\text { Test and FEA }(\mathrm{kN}) \\
P_{\mathrm{EXP}} \text { and } P_{\mathrm{FEA}}\end{array}$} & \multirow{3}{*}{$\begin{array}{l}P_{\mathrm{CDSM}} \\
(\mathrm{kN})\end{array}$} & \multirow{3}{*}{$\begin{array}{c}P_{\mathrm{MDSM}} \\
(\mathrm{kN})\end{array}$} & \multicolumn{2}{|c|}{ Comparison } \\
\hline & & & & & $P_{\text {EXP }}$ and $P_{\text {FEA }}$ & $P_{\text {EXP }}$ and $P_{\text {FEA }}$ \\
\hline & & & & & $P_{\mathrm{CDSM}}$ & $P_{\text {MDSM }}$ \\
\hline \multirow[t]{9}{*}{ This paper } & U90-300-35-A1 & 36.82 & 39.27 & 36.53 & 0.94 & 1.01 \\
\hline & U90 -300-35-A2 & 34.86 & 34.75 & 32.66 & 1.00 & 1.07 \\
\hline & U90-300-35-A3 & 34.23 & 35.82 & 33.64 & 0.96 & 1.02 \\
\hline & U120-360-50-A1 & 36.81 & 38.71 & 36.72 & 0.95 & 1.00 \\
\hline & U120-360-50-A2 & 34.86 & 38.96 & 36.99 & 0.89 & 0.94 \\
\hline & U120-360-50-A3 & 39.28 & 38.09 & 36.20 & 1.03 & 1.09 \\
\hline & U140-420-50-A1 & 38.24 & 40.62 & 38.68 & 0.94 & 0.99 \\
\hline & U140-420-50-A2 & 39.59 & 39.99 & 38.04 & 0.99 & 1.04 \\
\hline & U140-420-50-A3 & 38.82 & 40.80 & 38.84 & 0.95 & 1.00 \\
\hline
\end{tabular}




\begin{tabular}{|c|c|c|c|c|c|c|}
\hline & U140-450-35-A1 & 47.79 & 56.32 & 52.79 & 0.85 & 0.91 \\
\hline & U140-450-35-A2 & 48.15 & 54.08 & 50.84 & 0.89 & 0.95 \\
\hline & U140-450-35-A3 & 44.36 & 53.71 & 50.52 & 0.83 & 0.88 \\
\hline \multirow{9}{*}{ Mulligan [28] } & $\mathrm{C} 2$ & 32.69 & 33.91 & 31.52 & 0.96 & 1.04 \\
\hline & $\mathrm{C} 3$ & 34.69 & 34.75 & 32.68 & 1.00 & 1.06 \\
\hline & $\mathrm{C} 4$ & 31.58 & 34.21 & 32.26 & 0.92 & 0.98 \\
\hline & C5 & 35.06 & 37.72 & 36.08 & 0.93 & 0.97 \\
\hline & C6 & 35.09 & 38.01 & 36.36 & 0.92 & 0.97 \\
\hline & $\mathrm{C} 7$ & 40.74 & 43.98 & 41.97 & 0.93 & 0.97 \\
\hline & $\mathrm{C} 8$ & 40.92 & 49.28 & 47.25 & 0.83 & 0.87 \\
\hline & $\mathrm{C} 9$ & 36.47 & 37.45 & 35.67 & 0.97 & 1.02 \\
\hline & $\mathrm{C} 10$ & 37.90 & 40.78 & 39.11 & 0.93 & 0.97 \\
\hline \multirow[t]{34}{*}{ FEA } & U140-20-1.0 & 25.18 & 26.13 & 24.99 & 0.96 & 1.01 \\
\hline & U140-20-1.5 & 48.25 & 53.37 & 50.01 & 0.90 & 0.96 \\
\hline & U140-20-2.0 & 74.65 & 85.21 & 78.47 & 0.88 & 0.95 \\
\hline & U140-20-2.5 & 105.39 & 126.79 & 114.10 & 0.83 & 0.92 \\
\hline & U140-40-1.0 & 30.32 & 32.34 & 30.91 & 0.94 & 0.98 \\
\hline & U140-40-1.5 & 58.36 & 65.19 & 61.09 & 0.90 & 0.96 \\
\hline & U140-40-2.0 & 93.85 & 106.45 & 97.78 & 0.88 & 0.96 \\
\hline & U140-40-2.5 & 136.94 & 154.85 & 139.37 & 0.88 & 0.98 \\
\hline & U140-60-1.0 & 32.11 & 34.66 & 33.29 & 0.93 & 0.96 \\
\hline & U140-60-1.5 & 65.16 & 70.23 & 66.28 & 0.93 & 0.98 \\
\hline & U140-60-2.0 & 104.21 & 115.00 & 106.67 & 0.91 & 0.98 \\
\hline & U140-80-1.5 & 68.10 & 71.50 & 68.04 & 0.95 & 1.00 \\
\hline & U140-80-2.0 & 114.38 & 117.51 & 110.19 & 0.97 & 1.04 \\
\hline & U140-80-2.5 & 166.05 & 172.03 & 158.96 & 0.97 & 1.04 \\
\hline & U120-20-1.0 & 24.92 & 26.49 & 25.14 & 0.94 & 0.99 \\
\hline & U120-20-1.5 & 47.79 & 53.17 & 49.31 & 0.90 & 0.97 \\
\hline & U120-20-2.0 & 74.54 & 86.44 & 78.29 & 0.86 & 0.95 \\
\hline & U120-20-2.5 & 103.28 & 125.2 & 110.62 & 0.82 & 0.93 \\
\hline & U120-40-1.0 & 29.48 & 32.18 & 30.6 & 0.92 & 0.96 \\
\hline & U120-40-1.5 & 57.84 & 64.69 & 60.15 & 0.89 & 0.96 \\
\hline & U120-40-2.0 & 92.15 & 105.28 & 95.69 & 0.88 & 0.96 \\
\hline & U120-40-2.5 & 132.71 & 152.65 & 135.52 & 0.87 & 0.98 \\
\hline & U120-60-1.0 & 31.61 & 33.70 & 32.29 & 0.94 & 0.98 \\
\hline & U120-60-1.5 & 64.32 & 68.05 & 63.99 & 0.95 & 1.01 \\
\hline & U120-60-2.0 & 104.50 & 111.28 & 102.71 & 0.94 & 1.02 \\
\hline & U120-60-2.5 & 151.21 & 162.12 & 146.81 & 0.93 & 1.03 \\
\hline & U120-80-1.0 & 32.42 & 34.30 & 33.07 & 0.95 & 0.98 \\
\hline & U120-80-1.5 & 68.43 & 69.52 & 65.99 & 0.98 & 1.04 \\
\hline & U120-80-2.0 & 114.03 & 114.14 & 106.67 & 1.00 & 1.07 \\
\hline & U120-80-2.5 & 165.67 & 166.92 & 153.59 & 0.99 & 1.08 \\
\hline & U100-20-1.0 & 24.57 & 26.55 & 24.96 & 0.93 & 0.98 \\
\hline & U100-20-1.5 & 47.73 & 52.98 & 48.42 & 0.90 & 0.99 \\
\hline & U100-20-2.0 & 73.96 & 85.62 & 75.99 & 0.86 & 0.97 \\
\hline & U100-20-2.5 & 101.45 & 123.25 & 106.05 & 0.82 & 0.96 \\
\hline
\end{tabular}




\begin{tabular}{|c|c|c|c|c|c|}
\hline U100-40-2.5 & 130.70 & 148.17 & 129.55 & 0.88 & 1.01 \\
\hline U100-60-1.0 & 31.07 & 32.46 & 31.02 & 0.96 & 1.00 \\
\hline U100-60-1.5 & 64.10 & 65.43 & 61.30 & 0.98 & 1.05 \\
\hline U100-60-2.0 & 103.75 & 106.84 & 98.10 & 0.97 & 1.06 \\
\hline U100-60-2.5 & 149.15 & 155.39 & 139.78 & 0.96 & 1.07 \\
\hline U100-80-1.0 & 32.89 & 32.99 & 31.76 & 1.00 & 1.04 \\
\hline U100-80-1.5 & 66.80 & 66.85 & 63.31 & 1.00 & 1.06 \\
\hline U100-80-2.0 & 113.63 & 109.64 & 102.16 & 1.04 & 1.11 \\
\hline U100-80-2.5 & 163.90 & 160.19 & 146.83 & 1.02 & 1.12 \\
\hline U80-20-1.0 & 23.96 & 26.63 & 24.69 & 0.90 & 0.97 \\
\hline U80-20-1.5 & 46.99 & 52.68 & 47.12 & 0.89 & 1.00 \\
\hline U80-20-2.0 & 71.07 & 84.39 & 72.64 & 0.84 & 0.98 \\
\hline U80-20-2.5 & 93.49 & 120.38 & 99.39 & 0.78 & 0.94 \\
\hline U80-40-1.0 & 29.03 & 30.21 & 28.42 & 0.96 & 1.02 \\
\hline U80-40-1.5 & 56.80 & 60.31 & 55.15 & 0.94 & 1.03 \\
\hline U80-40-2.0 & 90.38 & 97.48 & 86.57 & 0.93 & 1.04 \\
\hline U80-40-2.5 & 123.92 & 140.48 & 120.96 & 0.88 & 1.02 \\
\hline U80-60-1.0 & 31.25 & 31.23 & 29.75 & 1.00 & 1.05 \\
\hline U80-60-1.5 & 65.58 & 62.84 & 58.59 & 1.04 & 1.12 \\
\hline U80-60-2.0 & 103.45 & 102.46 & 93.46 & 1.01 & 1.11 \\
\hline U80-60-2.5 & 145.84 & 166.60 & 150.27 & 0.88 & 0.97 \\
\hline U80-80-1.0 & 31.56 & 31.44 & 30.22 & 1.00 & 1.04 \\
\hline U80-80-1.5 & 69.00 & 63.61 & 60.12 & 1.08 & 1.15 \\
\hline U80-80-2.0 & 110.96 & 104.23 & 96.85 & 1.06 & 1.15 \\
\hline U80-80-2.5 & 155.99 & 152.16 & 138.98 & 1.03 & 1.12 \\
\hline Mean & & & & 0.93 & 1.01 \\
\hline SD & & & & 0.059 & 0.056 \\
\hline
\end{tabular}

Note: U80-80-2.5; U-short column; 80-the height of web; 80-the width of flange; 2.5-the thickness.

\section{Conclusions}

The calculation method to predict the ultimate capacity of CFS short columns was proposed in this paper, according to the experiment, the finite element analysis and the current direct strength method. By research of this paper, the following conclusions are summarized:

(1) The calculation results obtained from the current direct strength method have a great error and are unsafe compared with the results obtained by the tests, finite element parameter analysis, and other researchers' test data.

(2) The presented method in this paper provides accurate calculation results for the prediction of the ultimate capacity of CFS U-section short columns, that is, the calculation error and the discreteness is very small. The modified direct strength method is a design method that can be used for engineering design reference.

(3) Due to the lack of accurate and reasonable design method for ultimate capacity of CFS U-section columns in previous researches, therefore, the purpose of this paper is modify the direct strength method to apply to CFS U-section short columns, and lay the foundation for future research on the ultimate capacity of CFS built-up members.

\section{Acknowledgment}

The authors are sincerely appreciated to the financial support by the National Natural Science Foundation of China (Grant No. 51878055).

\section{References}

[1] Lu, Y., Zhou, T.H., Li, W.C., et al., "Novel local buckling formulae for cold-formed C-section columns considering end condition effect", Thin-walled structures, 116, 265-276, 2017.

[2] Jun Ye, Iman Hajirasouliha, Jurgen Becque., "Experimental investigation of local-flexural interactive buckling of cold-formed steel channel columns", Thin-walled structures, 125, 245-258, 2018

[3] Daniel C.T. Cardoso. and Guilherme C. de Salles., "Explicit equations for distortional buckling of cold-formed steel lipped channel columns", Thin-walled structures, 119, 925-933, 2017.

[4] Torabian S, Fratamico D C, Schafer B W., "Experimental response of cold-formed steel
Zee-section beam-columns", Thin-walled structures, 98, 496-517, 2016.

[5] Adi Susila. and Jimmy Tan., "Flexural strength performance and buckling mode prediction of cold-formed steel (C section)", Procedia Engineering, 125, 979-986, 2015.

[6] M. Bock. And E. Real., "Strength curves for web crippling design of cold-formed stainless steel hat sections", Thin-walled structures, 85, 93-105, 2014.

[7] K.F. Chung, H.C. Ho., "Analysis and design of lapped connections between cold-formed steel Z sections", Thin-walled structures, 43, 1071-1090, 2005.

[8] Young B. and Rasmussen K.J.R., "Test of fixed-ended plain channel column", Journey of Structural Engineering, 124 (2), 131-139, 1998.

[9] Fan S.G., Ding R.M., Han Y.L., Chen M.H., Liu C.L., and Tao Y.L., "Experimental study on bearing capacity of austenitic stainless steel lipped channel columns", Advanced Steel Construction, 16 (1), 65-76, 2020

[10] Baldassino N., Bernuzzi C. and Simoncelli M., "Experimental vs. theoretical design approaches for thin-walled cold-formed steel beam-columns", Advanced Steel Construction, 15 (1), 55-65, 2019

[11] AISI S100-2007., "North American specification for the design of cold-formed steel structural members", Washington: American Institute of Steel Construction, 2007.

[12] AS/NZS 4600:2005., "Cold-formed steel structures", Sydney: Australian Institute of Steel Construction, 2005.

[13] Ungermann D., Lübke, Sebastian., Brune B., "Tests and design approach for plain channels in local and coupled local-flexural buckling based on eurocode 3", Thin-Walled Structures 81, 108-120, 2014

[14] Loughlan J. and Yidris N., "The local-overall flexural interaction of fixed-ended plain channel columns and the influence on behavior of local conditions at the constituent plate ends", Thin-Walled Structures, 81, 132-137, 2014.

[15] Nguyen V B, Wang C J, Mynors D J, et al., "Compression tests of cold-formed plain and dimpled steel columns", Journal of Constructional Steel Research, 69 (1), 20-29, 2012.

[16] Duarte A P C. and Silvestre N., "A new slenderness-based approach for the web crippling design of plain channel steel beams", International Journal of Steel Structures, 13 (3), 421-434, 2013

[17] Young B., "Research on cold-formed steel columns", Thin-Walled Structures, 46 (7) 731-740, 2008.

[18] Young B., "Bifurcation analysis of thin-walled Plain channel compression members", Finite Elements in Analysis \& Design, 41 (2), 211-225, 2005.

[19] Young B. and Yan J., "Finite element analysis and design of fixed-ended plain channel columns", Finite Elements in Analysis and Design, 38 (6), 549-566, 2002.

[20] Pedro B. Dinis. and Eduardo M. Batista., "Local-distortional-global interaction in lippe channel columns experimental results, numerical simulations and design considerations", Thin-walled structures, 61, 2-13, 2012.

[21] GB50018-2002., "Technical Specification for Cold-formed Thin-walled Steel Structures", Beijing: China Planning Publishing House, 2002, (in Chinese).

[22] GB/T228.1-2010., "Tensile Test of Metal Materials Part 1: Room Temperature Test Methods", Beijing: China Standard Press, 2010, (in Chinese).

[23] ABAQUS, “Analysis user's manual”, Version 6.9. Dassault systems; 2010. 
[24] J. Zhang. and B. Young, "Finite element analysis and design of cold-formed steel built-up closed section columns with web stiffeners", Thin-Walled Structures, 131, 223-237, 2018.

[25] Schafer B.W. and Pekoz T, "Direct strength prediction of cold-formed steel members using numerical elastic buckling solution", Proceedings of the fourteenth international specialty conference on cold-formed steel structure, St. Louis, MO: 1998 69-76.

[26] Schafer B.W., "Review: The direct strength method of cold-formed steel member design", Journal of Constructional Steel Research, 64 (7), 766-778, 2008.

[27] Bebiano R., Pina P., Silvestre N., Camotim D., "GBTUL — buckling and vibration analysis of thin-walled members", Lisbon, Portugal: DECivil/IST, Technical University of Lisbon, 2008 .

[28] Mulligan G.P., "The Influence of local buckling on the structural behavior of singly-symmetric cold-formed steel columns”, Ithaca: Cornell University, 1983. 